\title{
Exploring exchange rate returns at different time horizons
}

\author{
Ramzi Nekhilia,*, Aslihan Altay-Salih" ${ }^{\mathrm{a}}$, Ramazan Gençay ${ }^{\mathrm{b}}$ \\ ${ }^{a}$ Faculty of Business Administration, Bilkent University, 06533 Ankara, Turkey \\ ${ }^{\mathrm{b}}$ Department of Economics, University of Windsor, Windsor, Ont., Canada N9B 3P4
}

Received 22 February 2002

\begin{abstract}
This paper explores and compares the empirical distribution of the US dollar-deutsche mark exchange rate returns with well-known continuous-times processes at different frequencies. We use a variety of parametric models to simulate the unconditional density of the exchange rate returns at different frequencies, and show that the studied models do not fit the empirical distribution of exchange rate returns at both the high and low frequencies.
\end{abstract}

(c) 2002 Elsevier Science B.V. All rights reserved.

PACS: 02.50.Ey; 02.70.Lq; 11.10.J

Keywords: Exchange rate returns; Continuous-time processes; Time scales

\section{Introduction}

Many models in continuous-time finance rely on the assumption of a specific stochastic process, while little attention is paid to the empirical fit of an assumed process to the actual data across different time scales. Consequently, the application of such statistical models to financial data would result in specification errors when the underlying data-generating process scales differently across time. This assumption can also lead to mispricing of financial assets, and can have serious implications on portfolio selection and risk management. There is now evidence that investors do have heterogeneous expectations differentiated according to their time dimensions (see Ref. [4]). The co-existence of short-term as well as long-term traders indicates that there are different time scales for different traders in the market. Therefore, different time scales can lead

\footnotetext{
* Corresponding author. Tel.: +90-312-290-2049; fax: +90-312-266-4958.

E-mail address: nekhili@bilkent.edu.tr (R. Nekhili).
} 
to different price formation processes, which have other effects such as volatility clustering and foreign exchange adjustment. However, investigating the scaling properties of foreign exchange returns and modelling its dynamics is far away from being trivial, and one recent promising attempt is the wavelet multi-scaling approach (see Ref. [7]).

The aim of this study is to investigate the performance of the well-known stochastic processes in fitting the empirical distribution of the exchange rate returns at different time scales. We start with estimating the parameters of the candidate processes at different time scales and proceed with simulating the empirical distributions of exchange rate returns from selected candidate processes. The theoretical distributions are then compared with the empirical distribution via a Kolmogorov-Smirnov goodness-of-fit test.

\section{Candidate processes for the exchange rate returns}

\subsection{Random walk $\operatorname{GARCH}(1,1)$}

Consider the following representation of the continuous-time logarithmic price process $P_{t}$, where $P_{t}$ is a dollar price of the foreign currency at time $t$ :

$$
\mathrm{d} P_{t} / P_{t}=\alpha \mathrm{d} t+\sigma \mathrm{d} W_{t},
$$

where $t \geqslant 0$ and $W_{t}$ denotes a standard Brownian motion. The mean, $\alpha$, and the variance, $\sigma$, are both defined per unit time. Moreover, consider the following continuoustime representation of the returns, defined as $X_{t}=\ln P_{t}-\ln P_{t_{0}}$ :

$$
\mathrm{d} X_{t}=\mu \mathrm{d} t+\sigma \mathrm{d} W_{t} .
$$

The drift part in Eq. (2), $\mu=\alpha-\frac{1}{2} \sigma^{2}$, can be omitted since the expected returns are equal to zero for all return horizons. Our estimation shows further that the drift is significantly equal to zero. In fact, Andersen et al. [1] argue that it is straightforward to allow for a drift or more general forms of conditional mean predictability but the assumption of no conditional mean provides a very good approximation for the high-frequency returns over $20 \mathrm{~min}$. In order to capture volatility clustering, we use the GARCH process for conditional volatility. Therefore, the random walk model with $\operatorname{GARCH}(1,1)$ specification for the exchange rate returns is presented as follows:

$$
\begin{aligned}
& \mathrm{d} X_{t}=\sigma_{t} \mathrm{~d} W_{t}=\sigma_{t} \varepsilon_{t}, \\
& \sigma_{t}^{2}=\alpha_{0}+\alpha_{1} \varepsilon_{t-1}^{2}+\alpha_{2} \sigma_{t-1}^{2},
\end{aligned}
$$

where $\varepsilon_{t}$ is assumed to follow a probability distribution with zero mean and unit variance, such as the standard normal distribution or the Student- $t$ distribution.

\subsection{Random walk with stochastic volatility}

The next model considered is the random walk with stochastic volatility. The volatility of the returns is assumed to follow an Ornstein-Uhlenbeck process, hence the returns 
Table 1

Moments of return distribution for USD-DEM

\begin{tabular}{llccr}
\hline Time interval & Mean $\left(\times 10^{4}\right)$ & SD $\left(\times 10^{4}\right)$ & Skewness & Kurtosis \\
\hline 30 min & -0.008 & 9.436 & -0.339 & 28.092 \\
$6 \mathrm{~h}$ & -0.120 & 31.704 & -0.067 & 12.269 \\
12 hours & -0.225 & 45.702 & -0.206 & 10.080 \\
24 hours & -0.469 & 65.270 & -0.250 & 7.137 \\
1 week & -3.961 & 133.034 & -0.210 & 4.487
\end{tabular}

This table provides estimates of the first four moments of the unconditional distribution at different time intervals for the USD-DEM returns for the period from January 2, 1995 to November 27, 1996. The original data consist of continuously recorded 5-min bid and ask prices obtained from the Olsen \& Associates database. The 5-min returns are calculated as the log difference of the prices and for each time interval, the returns are generated by aggregating the 5-min returns. We present the mean, the standard deviation, the skewness, and the kurtosis along with each time interval of $30 \mathrm{~min}, 6,12,24 \mathrm{~h}$ and 1 week. The USD-DEM returns are skewed to the right and exhibit an excess kurtosis decreasing from the $30 \mathrm{~min}$ to the weekly horizon.

are defined as follows:

$$
\begin{aligned}
& \mathrm{d} X_{t}=\sigma_{t} \mathrm{~d} W_{t}=\sigma_{t} \varepsilon_{t}, \\
& \mathrm{~d} \sigma_{t}=a\left(b-\sigma_{t}\right) \mathrm{d} t+\sigma_{v} \mathrm{~d} Z_{t}, \\
& \sigma_{t_{0}}=\sigma_{0},
\end{aligned}
$$

where $a>0, b>0, \sigma_{v}$ is the variance of the volatility, and the Wiener processes, $W_{t}$ and $Z_{t}$, are independent.

\subsection{Jump-Diffusion process}

The last process we consider is the parametric Jump-Diffusion process defined as

$$
\mathrm{d} X_{t}=\sigma \mathrm{d} W_{t}+\kappa_{t} \mathrm{~d} N_{t}
$$

where $\kappa_{t}$ is the jump and assumed to be identically and independently distributed and lognormal with mean $\theta$ and variance $\delta^{2} . N_{t}$ is a Poisson arrival process with parameter $\lambda$ as a mean number of information arrivals per unit time. It is assumed that upon the arrival of "abnormal" information, there is an instantaneous jump in the exchange rate of size $\kappa_{t}$, independent of $W_{t}$.

\section{The empirical data}

We use the US dollar-deutsche mark (USD-DEM) spot exchange rate since it is the most actively traded and quoted foreign currency. The USD-DEM spot rates are obtained from Olsen \& Associates database. The sample consists of continuously recorded 5-min bid and ask prices from January 2, 1995 through November 27, 1996 for a total of 138,816 observations. Each quote consists of a bid and ask price with a time stamp 

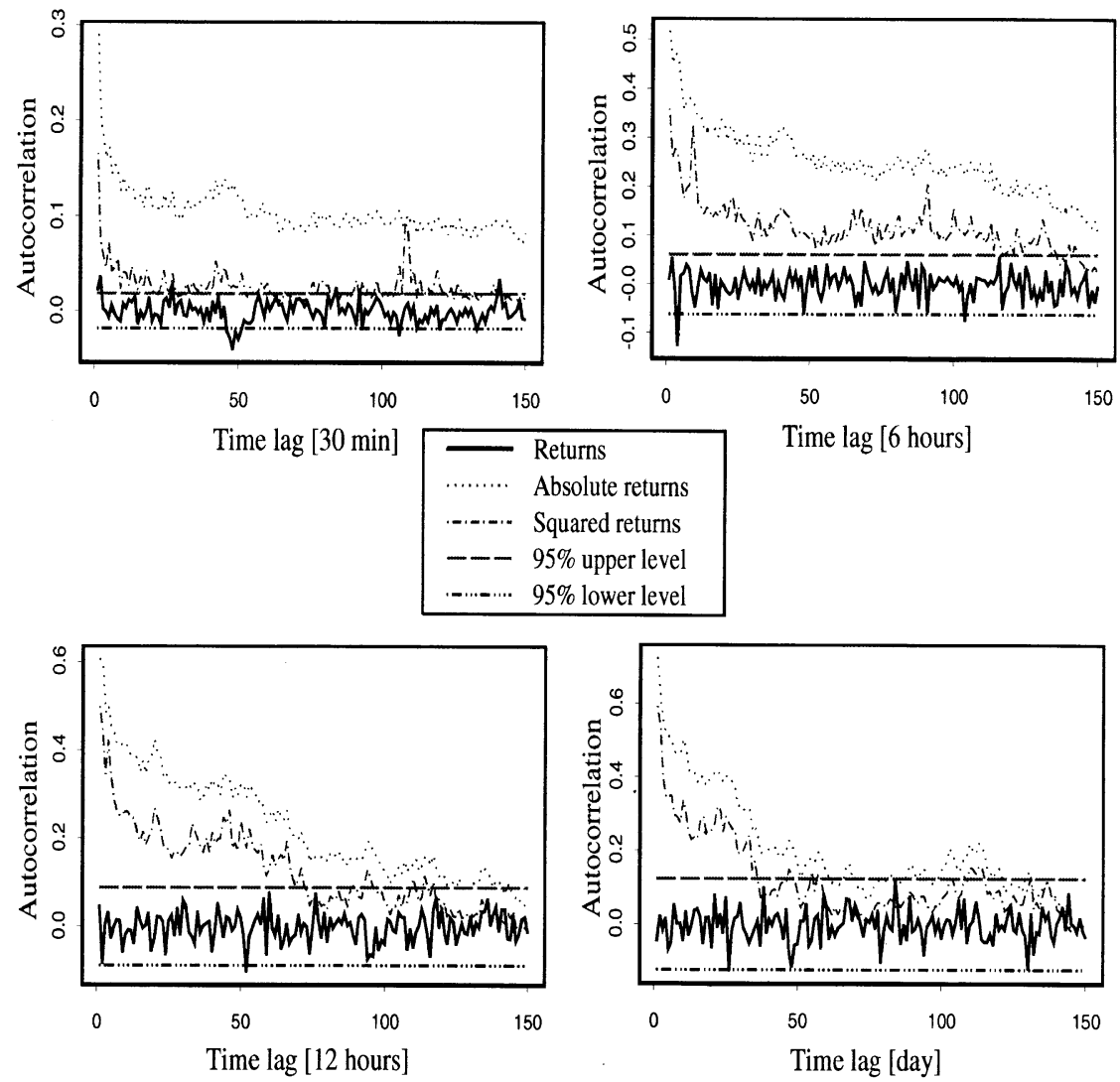

Fig. 1. Autocorrelation coefficients of the empirical returns. The figure present the autocorrelation coefficients of the USD-DEM returns from January 2, 1995 through November 27, 1996, for different time horizons, along with the corresponding autocorrelation coefficients of the realized absolute returns, the squared returns and the $95 \%$ significance level. The original data consists of continuously recorded 5-min bid and ask prices obtained from the Olsen \& Associates database. The 5-min returns are calculated as the $\log$ difference of the prices and for each time interval, the returns are generated by aggregating the 5-min returns.

to the nearest even second. The prices at each 5-min interval are obtained by linearly interpolating from the logarithmic average of the bid and ask for the two closest ticks as in Refs. [9,5]. The continuously compounded prices are the average of the logarithm of the bid and ask prices:

$$
P_{t}=\frac{1}{2}\left[\ln P(\text { bid })_{t}+\ln P(\text { ask })_{t}\right] \quad \text { for } t=1, \ldots, 138,816 .
$$

Not to confound the evidence of slow trading patterns over weekends (see Ref. [3]), we removed the weekend quotes from Friday 22:00 GMT to Sunday 22:00 GMT. The continuously compounded 5-min returns are calculated as the log difference of the prices:

$$
X_{t_{5}}=P_{t}-P_{t-1} \quad \text { for } t_{5}=1, \ldots, 138,815 .
$$


Table 2

Parameter estimates of a diffusion process with Gaussian errors

\begin{tabular}{llllll}
\hline Parameter & $30 \mathrm{~min}$ & $6 \mathrm{~h}$ & $12 \mathrm{~h}$ & $24 \mathrm{~h}$ & 1 week \\
\hline$\mu$ & 0 & 0 & 0 & $-1 \mathrm{E}-06$ & $-14.8 \mathrm{E}-05$ \\
& $(0.0)$ & $(0.0)$ & $(-0.0)$ & $(-0.0)$ & $(-0.1)$ \\
$\sigma$ & 0.0009 & 0.0031 & 0.0044 & 0.0063 & 0.0140 \\
& $(61.1)^{*}$ & $(26.5)^{*}$ & $(14.6)^{*}$ & $(11.0)^{*}$ & $(8.9)^{*}$ \\
Loglikelihood & 13,583 & 8703 & 3988 & 1812 & 279 \\
\hline
\end{tabular}

* Significant at 5\% level.

This table gives the maximum likelihood estimation of the parameter ( $t$-statistics are presented in parantheses) of a diffusion process with Gaussian errors for the USD-DEM returns from January 2, 1995 through November 27, 1996, at different time intervals. The original data consist of continuously recorded 5-min bid and ask prices obtained from the Olsen \& Associates database. The 5-min returns are calculated as the $\log$ difference of the prices and for each time interval, the returns are generated by aggregating the 5-min returns. The continuous-time return process is specified as $\mathrm{d} X_{t}=\mu \mathrm{d} t+\sigma \mathrm{d} W_{t}$, and the loglikelihood function is given by

$$
L=\frac{1}{2} \ln 2 \pi+\sum_{t=1}^{T}\left[\frac{1}{\sigma} \exp \left(\frac{-\left(X_{t}-\mu\right)^{2}}{2 \sigma^{2}}\right)\right] .
$$

The drift $\mu$ is highly insignificant at the $5 \%$ significance level showing that the return process is equivalent to a simple random walk.

To eliminate the seasonality, we filtered the raw 5 -min returns by removing holidays as in Ref. [1], and to avoid the bias that can be caused by the buying and selling intensions of the quoting institutions on the price changes observed at high frequencies (see Ref. [4]), we opted to work with 30-min aggregated returns and aggregate for other frequencies:

$$
X_{t_{30}}=\sum_{i=0}^{5} X_{t_{5-i}} \text { for } t_{30}=1, \ldots, 23,135 .
$$

We also construct the realized volatility from returns defined as the absolute returns at a certain time horizon. For instance, the 30 -min realized volatility is defined as follows:

$$
\sigma_{t_{30}}=\left|\sum_{i=0}^{5} X_{t_{s-i}}\right| \quad \text { for } t_{30}=1, \ldots, 23,135 .
$$

Table 1 gives an empirical estimation of the first four moments of the unconditional distribution at different time intervals for the empirical exchange rate returns. The returns are not normally distributed. They are skewed to the right and exhibit excess kurtosis consistent with the existence of fat tails of the empirical distribution. Clearly, the distribution of returns is increasingly fat-tailed as data frequency increases and hence shows instability.

Fig. 1 represents the autocorrelation coefficients of the empirical exchange rate returns at different frequencies up to 150 lags corresponding to more than 3 days. One 
Table 3

Parameter estimates of random walk-GARCH(1,1) model with Gaussian errors

\begin{tabular}{llllll}
\hline Parameter & $30 \mathrm{~min}$ & $6 \mathrm{~h}$ & $12 \mathrm{~h}$ & $24 \mathrm{~h}$ & 1 week \\
\hline$\alpha_{0}$ & $\begin{array}{l}4.25 \mathrm{E}-08 \\
(62.7)^{*}\end{array}$ & $\begin{array}{l}2.52 \mathrm{E}-08 \\
(4.1)^{*}\end{array}$ & $\begin{array}{l}4.80 \mathrm{E}-08 \\
(2.8)^{*}\end{array}$ & $\begin{array}{l}2.55 \mathrm{E}-07 \\
(2.2)^{*}\end{array}$ & $\begin{array}{l}-4.21 \mathrm{E}-07 \\
(-0.1)\end{array}$ \\
$\alpha_{1}$ & 0.220 & 0.021 & 0.019 & 0.032 & 0.065 \\
& $(82.1)^{*}$ & $(10.9)^{*}$ & $(7.3)^{*}$ & $(2.0)^{*}$ & $(1.0)$ \\
$\alpha_{2}$ & 0.777 & 0.975 & 0.977 & 0.961 & 0.925 \\
& $(407.3)^{*}$ & $(449.3)^{*}$ & $(350.8)^{*}$ & $(55.7)^{*}$ & $(5.7)^{*}$ \\
Loglikelihood & 130,762 & 8537 & 3909 & 1858 & 288 \\
\hline
\end{tabular}

* Significant at 5\% level.

This table gives the maximum likelihood estimation of the parameters ( $t$-statistics are presented in parantheses) of a random walk-GARCH(1,1) model with Gaussian errors for the USD-DEM returns from January 2, 1995 through November 27, 1996, at different time intervals. The original data consist of continuously recorded 5-min bid and ask prices obtained from the Oslen \& Associates database. The 5-min returns are calculated as the $\log$ difference of the prices and for each time interval, the returns are generated by aggregating the 5-min returns. The continuous-time return process is specified as $\mathrm{d} X_{t}=\sigma_{t} \mathrm{~d} W_{t}=\sigma_{t} \varepsilon_{t}$, the volatility as $\sigma_{t}^{2}=\alpha_{0}+\alpha_{1} \varepsilon_{t}^{2}+\alpha_{2} \sigma_{t-1}^{2}$, and the loglikelihood is given by

$$
L=-\frac{1}{2} \ln 2 \pi+\sum_{t=1}^{T}\left[\frac{1}{\sigma_{t}} \exp \left(\frac{-X^{2}}{2 \sigma_{t}^{2}}\right)\right] .
$$

The parameters are significant at the $5 \%$ significance level with an exception at the weekly time interval. Moreover, as the frequency increases, the estimates for $\alpha_{1}+\alpha_{2}$ are close to unity, and thus approaching the long-term volatility model of an integrated GARCH process.

can observe that the absolute and the squared returns for the empirical return series have a significant autocorrelation for small time lags (until $6 \mathrm{~h}$ ), indicating the existence of volatility clustering. Moreover, there is a positive autocorrelation in the 30 -min returns (see Fig. 1) showing that the trades are positively correlated, i.e. a trade at the ask is likely to be followed by another at the ask (see Ref. [8] for more details).

\section{Methodolgy}

\subsection{Estimations}

Table 2 provides the maximum likelihood estimation of the parameters of the diffusion process with Gaussian innovations (Eq. (2)). The drift is highly insignificant, confirming our assumption that the expected returns are equal to zero for the time intervals studied, namely $30 \mathrm{~min}, 6,12,24 \mathrm{~h}$ and weekly interval. This comes to support the assumption of Andersen et al. [1] of no dynamics in the mean of the intraday returns at 30-min time horizon. In Tables 3 and 4, we estimate, respectively, the parameters of the random walk-GARCH$(1,1)$ with Gaussian errors and the random 
Table 4

Parameter estimates of random walk-GARCH(1,1) model with Student- $t$ errors

\begin{tabular}{|c|c|c|c|c|c|}
\hline Parameter & $30 \mathrm{~min}$ & $6 \mathrm{~h}$ & $12 \mathrm{~h}$ & $24 \mathrm{~h}$ & 1 week \\
\hline$\alpha_{0}$ & $\begin{array}{l}6.61 \mathrm{E}-08 \\
(15.97)^{*}\end{array}$ & $\begin{array}{l}5.31 \mathrm{E}-08 \\
(1.69)\end{array}$ & $\begin{array}{l}6.51 \mathrm{E}-08 \\
(1.16)\end{array}$ & $\begin{array}{l}2.31 \mathrm{E}-07 \\
(0.98)\end{array}$ & $\begin{array}{l}-1.7 \mathrm{E}-06 \\
(-0.25)\end{array}$ \\
\hline$\alpha_{1}$ & $\begin{array}{l}0.338 \\
(20.39)^{*}\end{array}$ & $\begin{array}{l}0.037 \\
(2.89)^{*}\end{array}$ & $\begin{array}{l}0.020 \\
(2.46)^{*}\end{array}$ & $\begin{array}{l}0.031 \\
(2.18)^{*}\end{array}$ & $\begin{array}{l}0.019 \\
(0.63)\end{array}$ \\
\hline$\alpha_{2}$ & $\begin{array}{l}0.680 \\
(72.09)^{*}\end{array}$ & $\begin{array}{l}0.971 \\
(145.53)^{*}\end{array}$ & $\begin{array}{l}0.979 \\
(141.39)^{*}\end{array}$ & $\begin{array}{l}0.963 \\
(62.35)^{*}\end{array}$ & $\begin{array}{l}0.978 \\
(12.96)^{*}\end{array}$ \\
\hline$v$ & $\begin{array}{l}3.266 \\
(16.53)^{*}\end{array}$ & $\begin{array}{l}2.649 \\
(3.48)^{*}\end{array}$ & $\begin{array}{l}3.100 \\
(3.35)^{*}\end{array}$ & $\begin{array}{l}3.930 \\
(2.65)^{*}\end{array}$ & $\begin{array}{l}5.400 \\
(1.24)\end{array}$ \\
\hline Loglikelihood & 133,840 & 8788 & 4004 & 1808 & 282 \\
\hline
\end{tabular}

* Significant at 5\% level.

This table gives the maximum likelihood estimation of the parameters ( $t$-statistics are presented in parantheses) of a random walk-GARCH(1,1) model with Student- $t$ errors for the USD-DEM returns from January 2, 1995 through November 27, 1996, at different time intervals. The original data consist of continuously recorded 5-min bid and ask prices obtained from the Olsen \& Associates database. The 5-min returns are calculated as the $\log$ difference of the prices and for each time interval, the returns are generated by aggregating the 5-min returns. The continuous-time return process is specified as $\mathrm{d} X_{t}=\sigma_{t} \mathrm{~d} W_{t}=\sigma_{t} \varepsilon_{t}$, the volatility as $\sigma_{t}^{2}=\alpha_{0}+\alpha_{1} \varepsilon_{t-1}^{2}+\alpha_{2} \sigma_{t-1}^{2}$, and the loglikelihood is given by,

$$
L=T\left[\ln \Gamma\left(\frac{v+1}{2}\right)-\ln \Gamma\left(\frac{v}{2}\right)-\frac{1}{2} \ln v \pi\right]-\frac{v+2}{2} \sum_{t=1}^{T} \ln \left[1+\left(\frac{X_{t}}{\sigma_{t} \sqrt{v}}\right)^{2}\right]
$$

where $v$ is the degree of freedom. With an exception of the weekly time horizon, all of the parameters are significant at the $5 \%$ significance level, and the sum of the ARCH and GARCH terms $\left(\alpha_{1}+\alpha_{2}\right)$ is close to unity, approaching the long-term volatility model of an integrated GARCH process.

walk-GARCH( $(1,1)$ with Student- $t$ innovations. We notice that the estimates for $\alpha_{1}+\alpha_{2}$ are close to unity as frequency increases, thus approaching the long-term volatility model of Engle and Bollerslev [6]. ${ }^{1}$ This indicates the presence of different market components corresponding to different time horizons. Therefore, we can argue that the standard GARCH volatility model may not be able to capture the heterogeneity of traders at different frequencies.

Table 5 presents the coefficient estimates of the Jump-Diffusion process for different time horizons. ${ }^{2}$ We find that the intensity of jumps varies significantly from $0.17 \%$ for $30 \mathrm{~min}$ to $0.05 \%$ for $12 \mathrm{~h}$, and disappears for 1 day and 1 week time intervals. This

\footnotetext{
${ }^{1}$ Some recent evidence suggests that the long-run dependencies in financial market volatility may be better characterized by a fractionally integrated GARCH, or FIGARCH model (see Ref. [2]). Since we focus on short-term volatility, we shall not consider complicated specifications of the volatility and leave them for possible extensions.

${ }^{2}$ We also tried the estimation using the Jump-Diffusion process and the $\operatorname{GARCH}(1,1)$ volatility, but the estimates were insignificant.
} 
Table 5

Parameter estimates of Jump-Diffusion process

\begin{tabular}{llllll}
\hline Parameter & $30 \mathrm{~min}$ & $6 \mathrm{~h}$ & $12 \mathrm{~h}$ & $24 \mathrm{~h}$ & 1 week \\
\hline$\sigma$ & 0.00050 & 0.00153 & 0.00199 & 0.00639 & 0.01433 \\
& $(47.34)^{*}$ & $(15.00)^{*}$ & $(6.89)^{*}$ & $(18.04)^{*}$ & $(8.91)^{*}$ \\
$\theta$ & -0.00003 & 0.00007 & 0.00012 & -0.00015 & -0.00020 \\
& $(-0.45)$ & $(1.07)$ & $(1.16)$ & $(-0.01)$ & $(-0.05)$ \\
$\delta$ & 0.00185 & 0.00125 & 0.00154 & 0.00001 & 0.00358 \\
& $(21.29)^{*}$ & $(16.31)^{*}$ & $(14.05)^{*}$ & $(0.00)$ & $(0.03)$ \\
$\lambda$ & 0.00175 & 0.00037 & 0.00053 & 0.01475 & 0.01244 \\
& $(13.13)^{*}$ & $(7.42)^{*}$ & $(5.78)^{*}$ & $(0.02)$ & $(0.09)$ \\
Loglikelihood & -27802 & -1381 & -872 & -485 & -176 \\
\hline
\end{tabular}

* Significant at 5\% level.

This table gives the maximum likelihood estimation of the parameters ( $t$-statistics are presented in parantheses) of a Jump-Diffusion process for the USD-DEM returns from January 2, 1995 through November 27, 1996, at different time intervals. The original data consist of continuously recorded 5-min bid and ask prices obtained from the Olsen \& Associates database. The 5-min returns are calculated as the log difference of the prices and for each time interval, the returns are generated by aggregating the 5-min returns. The continuous-time return process is specified as $\mathrm{d} X_{t}=\sigma_{t} \mathrm{~d} W_{t}+\kappa_{t} \mathrm{~d} N_{t}$, where $\kappa_{t}$ is the jump and assumed to be identically and independently distributed and lognormal with mean $\theta$ and variance $\delta^{2}$. $N_{t}$ is a Poisson arrival process with parameter $\lambda$ as a mean number of information arrivals per unit time. It is assumed that upon the arrival of "abnormal" information there is an instantaneous jump in the exchange rate of size $\kappa_{t}$, independent of $W_{t}$. The loglikelihood is given by

$$
L=-T \lambda-\frac{T_{i}}{2} \ln 2 \pi+\sum_{t=1}^{T} \ln \left[\sum_{j=0}^{n} \frac{\lambda^{j}}{j} \frac{1}{\sqrt{\sigma^{2}+\delta^{2} j}} \exp \left(\frac{-\left(X_{t}-\theta_{j}\right)^{2}}{2\left(\sigma^{2}+\delta^{2} j\right)}\right)\right] .
$$

The intensity of jumps $(\lambda)$ varies significantly from $0.17 \%$ for $30 \mathrm{~min}$ to $0.05 \%$ for $12 \mathrm{~h}$, and disappears for 1 day and 1 week time interval. This shows that, at daily and weekly frequency, the Jump-Diffusion process behaves as a simple diffusion process.

concludes that the impact of news on traders, such as the fundamental macro-economic information or the intervention of domestic and foreign central banks, differs according to the time horizon.

Finally, Table 6 presents the coefficient estimates of the Ornstein-Uhlenbeck volatility process. The table shows the significance of the mean reverting coefficients and shows the speed of reversion ranges from $0.06 \%$ for the $30 \mathrm{~min}$ horizon to a higher value of $1 \%$ for the weekly horizon.

\subsection{Simulations and tests}

The simulated return distributions of the four candidate process are obtained using a Monte Carlo simulation procedure with the parameter estimates from the empirical data. 
Table 6

Parameter estimates of Ornstein-Uhlenbeck volatility model

\begin{tabular}{llllll}
\hline Parameter & $30 \mathrm{~min}$ & $6 \mathrm{~h}$ & $12 \mathrm{~h}$ & $24 \mathrm{~h}$ & 1 week \\
\hline$a$ & 1.1690 & 1.9860 & 2.3200 & 1.6170 & 210.4810 \\
& $(26.1)^{*}$ & $(32.6)^{*}$ & $(24.9)^{*}$ & $(36.5)^{*}$ & $(55.1)^{*}$ \\
$b$ & 0.0006 & 0.0019 & 0.0029 & 0.0044 & 0.0099 \\
& $(88.9)^{*}$ & $(112.24)^{*}$ & $(123.2)^{*}$ & $(120.0)^{*}$ & $(154.0)^{*}$ \\
$\sigma_{v}$ & 0.0111 & 0.0047 & 0.0072 & 0.0083 & 0.1610 \\
& $(42.1)^{*}$ & $(52.1)^{*}$ & $(48.0)^{*}$ & $(71.4)^{*}$ & $(58.5)^{*}$ \\
Loglikelihood & 140,572 & 111,022 & 102,783 & 95,380 & 75,756 \\
\hline *Significant & & & & &
\end{tabular}

* Significant at 5\% level.

This table gives the maximum likelihood estimation of the parameters ( $t$-statistics are presented in parantheses) of an Ornstein-Uhlenbeck process for the realized volatility. The volatility is defined as the absolute USD-DEM returns from January 2, 1995 through November 27, 1996, at different time intervals. The original data consist of continuously recorded 5-min bid and ask prices obtained from the Olsen \& Associates database. The 5-min returns are calculated as the log difference of the prices and for each time interval, the returns are generated by aggregating the 5-min returns. The returns process is defined as $\mathrm{d} X_{t}=\sigma_{t} \mathrm{~d} W_{t}$, the volatility process as $\mathrm{d} \sigma_{t}=a\left(b-\sigma_{t}\right) \mathrm{d} t+\sigma_{v} \mathrm{~d} Z_{t}$, where $\sigma_{t_{0}}=\sigma_{0}, a>0, b>0, \sigma_{v}$ is the variance of the volatility, and the Wiener processes, $W_{t}$ and $Z_{t}$, are independent. The loglikelihood function for the volatility process is given by

$$
L=-\frac{1}{2} \ln 2 \pi-\frac{1}{2} \ln \sigma_{v}^{2} \frac{1-\mathrm{e}^{-2 a}}{2 a}-\frac{1}{2} \sum_{t=1}^{T} \frac{\left[\sigma_{t}-\mathrm{e}^{-a} \sigma_{t-1}-b\left(1-\mathrm{e}^{-a}\right)\right]^{2}}{\sigma_{v}^{2}\left(1-\mathrm{e}^{-2 a} / 2 a\right)} .
$$

All the parameters at different frequencies are significant at the 5\% significance level. For instance, the mean reverting coefficient (a) is highly significant, and the speed of reversion (b) ranges from $0.06 \%$ for the 30 min horizon to a higher value of $1 \%$ for the weekly horizon.

The simulated distributions are contrasted against the empirical distribution in terms of their autocorrelation plots and via a Kolmogorov-Smirnov goodness-of-fit test.

Fig. 2 shows the autocorrelation coefficients estimated from the simulated 30-min returns from, respectively, a random walk-GARCH(1,1) with Gaussian errors, a random walk-GARCH $(1,1)$ with Student- $t$ error, a Jump-Diffusion and a random walk with stochastic volatility, along with the corresponding autocorrelation coefficients of the realized absolute returns, the squared returns and the $95 \%$ significance levels. We observe significant autocorrelation in the simulated absolute and squared returns for the random walk-GARCH(1,1) with Gaussian and Student- $t$ errors up to certain lags and then damping for further lags up to 3 days. For the Jump-Diffusion and the random walk with stochastic volatility, we observe that the autocorrelations for different return series are alternating between significant and insignificant coefficients. We can prematurely state that only the random walk-GARCH$(1,1)$ process figure as a good candidate for the exchange rate returns.

In Table 7, we present the Kolomogorov-Smirnov goodness-of-fit values to test whether the simulated return distributions and the empirical distribution are significantly different. If two empirical cumulative distribution functions, $F_{1}$ and $F_{2}$, are to 
Random walk GARCH(1,1) with Gaussian errors
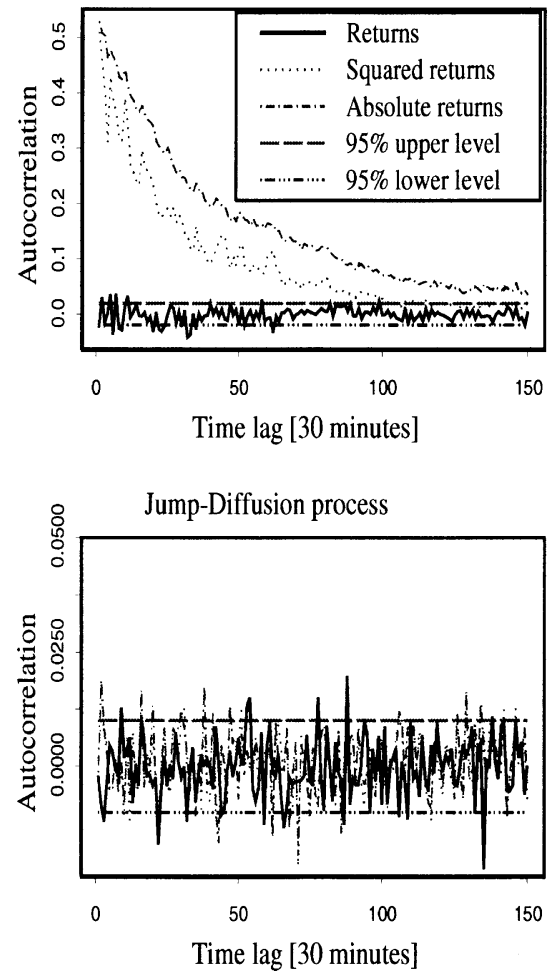

Random walk GARCH(1,1) with Student-t errors
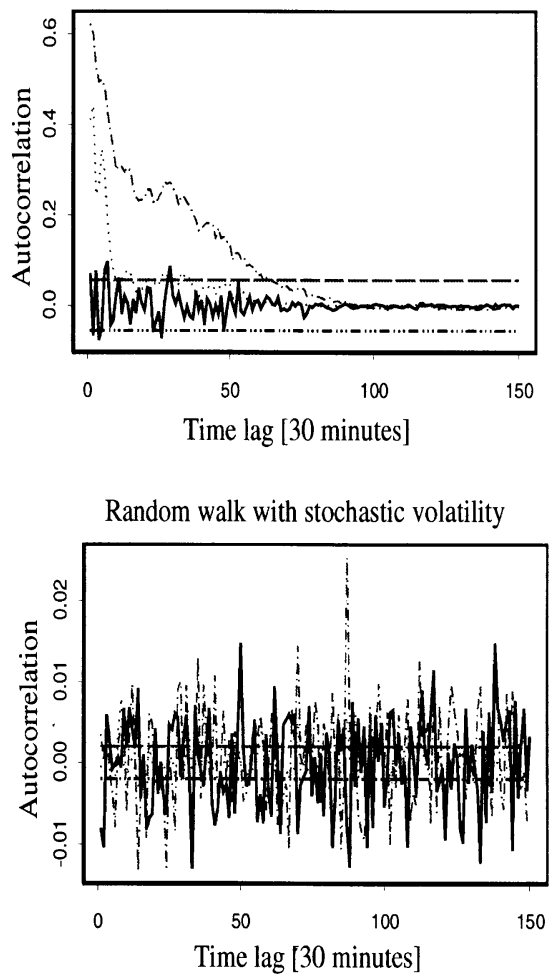

Fig. 2. Autocorrelation coefficients of the simulated returns. The figures plot the autocorrelation coefficients estimated from simulated half-hour return series generated from, respectively, a random walk- $\operatorname{GARCH}(1,1)$ with Gaussian errors, a random walk-GARCH $(1,1)$ with Student- $t$ errors, a Jump-Diffusion and a random walk with stochastic volatility model, along with the corresponding autocorrelation coefficients of the realized absolute returns, the squared returns and the $95 \%$ significance levels. The simulated return distributions are obtained using a Monte Carlo simulation procedure with the estimated parameters from the empirical data.

be compared, the two-sided test is defined as

$$
\begin{aligned}
& \mathrm{H}_{0}: F_{1}(x)=F_{2}(x) \text { for all } x \\
& \mathrm{H}_{1}: F_{1}(x) \neq F_{2}(x) \text { for at least one value of } x .
\end{aligned}
$$

As Table 7 demonstrates, none of the distributions, at different time intervals, capture the properties of the empirical distribution of returns at a $5 \%$ significance level. The exception can be seen with the 1 week time interval and where the random walk-GARCH(1,1) with Student- $t$ errors and the Jump-Diffusion process can be considered good candidates for the empirical distribution of the exchange rate returns ( $p$-value greater than 0.05 ). 
Table 7

Kolmogorov-Smirnov goodness of-fit test

\begin{tabular}{|c|c|c|c|c|c|}
\hline Time interval & $30 \mathrm{~min}$ & $6 \mathrm{~h}$ & $12 \mathrm{~h}$ & $24 \mathrm{~h}$ & 1 week \\
\hline $\begin{array}{l}\text { Random walk } \\
\text { GARCH( }(1,1) \text { with } \\
\text { Gaussian errors }\end{array}$ & $\begin{array}{r}0.137 \\
(0.00)\end{array}$ & $\begin{array}{r}0.138 \\
(0.00)\end{array}$ & $\begin{array}{r}0.157 \\
(0.00)\end{array}$ & $\begin{array}{c}0.174 \\
(0.00)\end{array}$ & $\begin{array}{r}0.220 \\
(0.01)\end{array}$ \\
\hline $\begin{array}{l}\text { Random walk } \\
\text { GARCH }(1,1) \text { with } \\
\text { Student- } t \text { errors }\end{array}$ & $\begin{array}{r}0.014 \\
(0.01)\end{array}$ & $\begin{array}{r}0.059 \\
(0.00)\end{array}$ & $\begin{array}{r}0.063 \\
(0.03)\end{array}$ & $\begin{array}{r}0.100 \\
(0.01)\end{array}$ & $\begin{array}{r}0.160 \\
(0.15)\end{array}$ \\
\hline $\begin{array}{l}\text { Random walk } \\
\text { with stochastic } \\
\text { volatility }\end{array}$ & $\begin{array}{r}0.499 \\
(0.00)\end{array}$ & $\begin{array}{r}0.499 \\
(0.00)\end{array}$ & $\begin{array}{r}0.497 \\
(0.00)\end{array}$ & $\begin{array}{r}0.501 \\
(0.00)\end{array}$ & $\begin{array}{r}0.515 \\
(0.00)\end{array}$ \\
\hline Jump-Diffusion & $\begin{array}{r}0.058 \\
(0.00)\end{array}$ & $\begin{array}{r}0.068 \\
(0.00)\end{array}$ & $\begin{array}{r}0.071 \\
(0.01)\end{array}$ & $\begin{array}{r}0.094 \\
(0.02)\end{array}$ & $\begin{array}{r}0.110 \\
(0.57)\end{array}$ \\
\hline
\end{tabular}

This table gives the Kolmogorov-Smirnov goodness-of-fit statistic to test whether the cumulative frequency distribution of the USD-DEM return distribution is significantly different to the cumulative frequency distributions of the simulated returns generated from the different stochastic processes. The simulated return distributions are obtained using a Monte Carlo simulation procedure with the estimated parameters from the empirical data. For different time horions, the two-sample Kolmogorov-Smirnov statistics are given and their $p$-values are in parantheses. Obviously, none of the distributions, at different time intervals, capture the properties of the USD-DEM distribution of returns at a 5\% significance level. The exception can be seen with the 1 week time interval and where the random walk-GARCH$(1,1)$ with Student- $t$ errors and the Jump-Diffusion process can be considered good candidates for the empirical distribution of the exchange rate returns ( $p$-value greater than 0.05$)$.

\section{Conclusions}

This paper presents evidence that the empirical distribution of returns behaves differently at different frequencies. In fact, different traders who exist in the market do not react the same way to different flows of information. Furthermore, we see that the simulated return distributions do not replicate the empirical distribution according to the Kolmogorov-Smirnov goodness-of-fit test at the 5\% significance level, with an exception for the random walk-GARCH$(1,1)$ with student- $t$ errors and the Jump-Diffusion model at weekly frequency. Finally, none of the studied models fit the empirical distribution of exchange rate returns at both the high and low frequencies. Broadening the analysis to several different exchange rates would determine whether the results of this paper could be generalized to the currency market in its entirety.

\section{Acknowledgements}

Ramazan Gençay gratefully acknowledges financial support from the Natural Sciences and Engineering Research Council of Canada and the Social Sciences and Humanities Research Council of Canada. The paper has also benefited from the 
comments of the seminar participants at the 2001 EFMA Doctoral Seminar in Lugano, Switzerland.

\section{References}

[1] T.G. Andersen, T. Bollerslev, F.X. Diebold, P. Labys, The distribution of realised exchange rate volatility, J. Am. Stat. Assoc. 96 (2001) 42-55.

[2] A. Beltratti, C. Morana, Computing value at risk with high frequency data, J. Empirical Finance 6 (1999) 431-455.

[3] T. Bollerslev, I. Domowitz, Trading patterns and prices in the interbank foreign exchange market, J. Finance 48 (1993) 1421-1443.

[4] M.M. Dacorogna, R. Gençay, U.A. Müller, R.B. Olsen, O.V. Pictet, An Introduction to High Frequency Finance, Academic Press, New York, 2001.

[5] M.M. Dacorogna, U.A. Müller, R.J. Nagler, R.B. Olsen. O.V. Pictet, A geographical model for the daily and weekly seasonal volatility in the foreign exchange markets, J. Int. Money Finance 12 (1993) 413-438.

[6] R.F. Engle, T. Bollerslev, Modelling the persistence of conditional variances, Econom. Rev. 5 (1986) $1-50$

[7] R. Gençay, F. Selcuk, B. Whitcher, An Introduction to Wavelets and Other Filtering Methods in Finance and Economics, Academic Press, New York, 2001.

[8] C.A.E. Goodhart, M. O'Hara, High frequency data in financial markets: issues and applications, J. Empirical Finance 4 (1997) 73-114.

[9] U.A. Müller, M.M. Dacorogna, R.B. Olsen, O.V. Pictet, M.S. Schwartz, C. Morgenegg, Statistical study on foreign exchange rates, empirical evidence of a price change scaling law, an intra-day analysis, J. Banking Finance 14 (1990) 1189-1208. 